\title{
MÚSICA E POESIA SOB O OLHAR SINCRÔNICO DE AUGUSTO DE CAMPOS ${ }^{1}$ MUSIC AND POETRY THROUGH AUGUSTO DE CAMPOS' SYNCRHONIC EYE
}

\author{
Expedito Ferraz Júnior ${ }^{2}$ \\ UFPB - Universidade Federal da Paraíba
}

\begin{abstract}
RESUMO: Este artigo discute as relações entre poesia e música e as possibilidades suscitadas pela visão sincrônica da arte literária que emergem da prática criativa de Augusto de Campos. Tomando como ponto de partida a leitura do poema "Coisa", publicado na coletânea Despoesia (1994), propusemo-nos a seguir as pistas do seu mosaico de referências para construir algumas hipóteses interpretativas acerca da poética que orienta, na obra do poeta paulista, a escolha de interlocutores literários dispersos ao longo do tempo, desde um passado distante até os dias atuais.
\end{abstract}

PALAVRAS-CHAVE: poesia; música; sincronia; Augusto de Campos.

ABSTRACT: This article discusses the relationship between poetry and music, and the possibilities raised by the synchronic view of literary art that emerges from Augusto de Campos's creative practice. Taking the reading of the poem "Coisa" - published in the anthology Despoesia (1994) - as a starting point, we try to follow the clues in its mosaic of references to build some interpretative hypotheses about the poetics that rule the poet's choices of his literary interlocutors, which are spread over time, from distant past to the present days.

KEYWORDS: poetry; music; synchrony; Augusto de Campos.

\footnotetext{
${ }^{1} \mathrm{O}$ presente trabalho retoma e amplia alguns tópicos presentes na tese de doutorado que apresentamos em 2003 ao Programa de Pós-Graduação em Letras da UFPB, bem como em artigos que publicamos esparsamente sobre a obra do poeta paulista Augusto de Campos.

${ }^{2}$ Doutor em Letras. Professor de Literatura Brasileira e Teoria da Literatura do Departamento de Letras Clássicas e Vernáculas da Universidade Federal da Paraíba. Professor do Programa de Pós-Graduação em Letras da UFPB, atuando na linha de pesquisa "Estudos Semióticos", Área de Linguagem e Cultura. E-mail: expeditoferraz@uol.com.br
} 


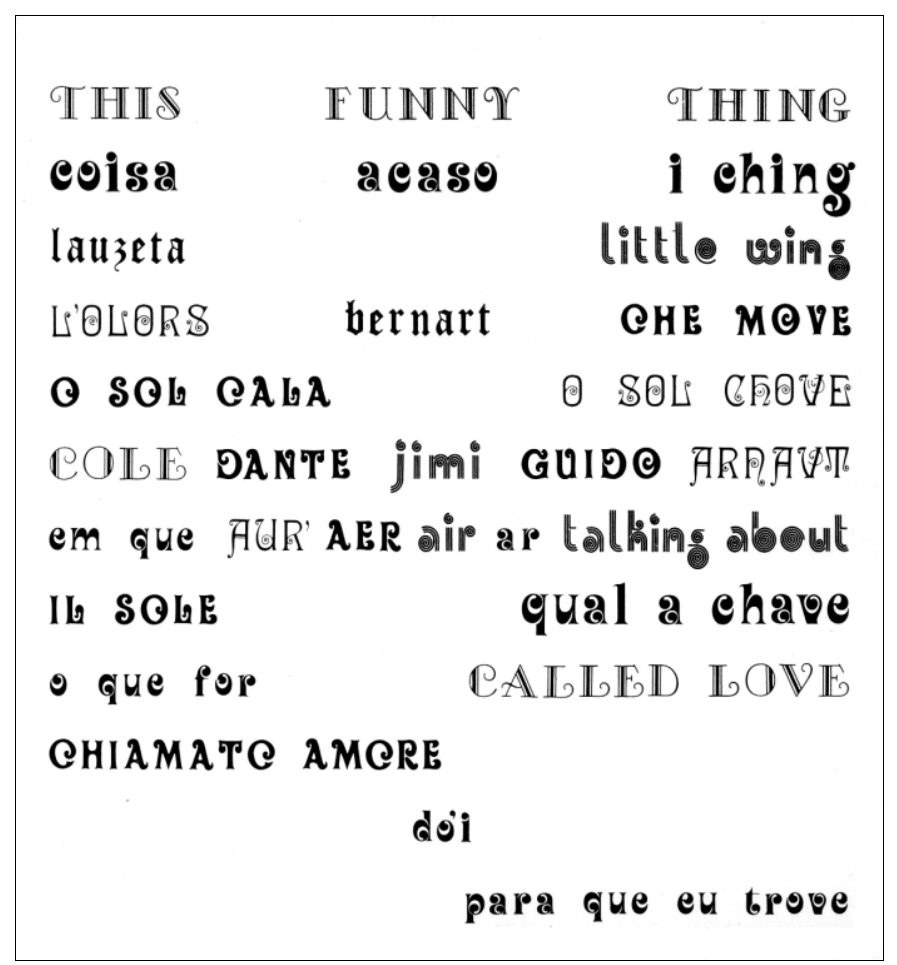

Figura 1 - "Coisa”, Augusto de Campos (1994)

O poema reproduzido acima integra a coletânea Despoesia, de Augusto de Campos (Perspectiva, 1994), precisamente a última das quatro seções de poemas do livro intituladas respectivamente "expoemas", "intraduções", "profilogramas" e "despoemas" - e a única em cujo título ganha reforço o prefixo de negação que já se via na capa do volume. Em "Coisa", essa negatividade começa a se impor à leitura sob a forma de uma aparente desordem na distribuição dos elementos gráficos pela página, o que faz desse um dos textos mais difíceis de ler em todo o conjunto do livro. Se não recorre propriamente à desconstrução visual dos signos (como se vê no último poema do livro), o poeta emprega aqui uma grande variedade de fontes que, ao primeiro olhar, se confundem e parecem destinadas a perturbar qualquer fluência na leitura, apresentando-se em vez disso como uma colagem de fragmentos que se intercalam. Para maior inquietação do leitor, esses fragmentos, quando lidos, vão compor um painel plurilinguístico pontuado de referências nominais não menos heterogêneas: Bernart, Cole, Dante, Jimi, Guido, Arnaut - citações que convidam a uma laboriosa pesquisa. Esse impacto inicial, em que ruídos e indefinições prevalecem sobre a leitura, ao mesmo tempo em que justificam os neologismos que os definem como forma negativa de comunicação poética (despoema, despoesia), também endossa a semântica da indefinição que marca o título do poema: chamamos de "coisa" aquilo cujo nome não sabemos; as formas que não reconhecemos e que, portanto, não podemos nomear; as sensações que não conseguimos traduzir. A propósito, "a Coisa" (das Ding) é como Freud chamou o objeto de desejo ideal para o qual passamos a vida a construir representações.

Mas ao leitor desafiado só cabe enfrentar o enigma, num processo de decifração semiótica que se iniciará com a descoberta de elementos regulares em meio ao caos aparente do poema. As primeiras regularidades se encontram ainda no nível sensorial da leitura: seja nas rimas, que forjam uma espécie de panlinguismo poético, produzindo identidades sonoras entre códigos distintos; seja no aspecto visual, em que a coincidência das fontes gráficas orienta o puzzle intertextual do poema, indicando relações entre autores e fragmentos que se espalham pelo texto. 


\title{
1. This funny thing...
}

A primeira citação, em língua inglesa: This funny thing... called love, talvez surpreenda por aludir, não a um poeta, no sentido estrito e parcial em que geralmente empregamos o termo, mas a um músico. Refere-se à canção What is this thing called love, ${ }^{3}$ do compositor norte-americano Cole Porter. ${ }^{4}$ A escolha não é aleatória: lá estão, entrelaçados, o tema do enigma e o da inefabilidade do amor, dois dos motivos que o poema de Augusto desenvolve, como veremos, numa viagem para frente e para trás na história do que chamamos de Lírica. ${ }^{5}$

\author{
What is this thing called love? \\ This funny thing called love? \\ Just who can solve its mystery, \\ Why should it make a fool of me?
}

Os demais fragmentos na língua inglesa trazem referências ao guitarrista Jimi Hendrix, o que assinala ousadia ainda maior: a remissão ao blues Little wing aparece numa inusitada associação com a palavra "lauzeta", extraída da canção "Quant vey la lauzeta" ("ao ver a ave leve mover / alegre as alas contra a luz...") (CAMPOS, 1988, p. 82-87), ${ }^{6}$ do trovador provençal Bernart de Ventadorn (século XII). Aqui, o emparelhamento de construções semanticamente afins (little wing / ave leve... alas), mas tão distantes no tempo e tão diversas quanto aos seus condicionantes históricos, encerra um gesto de provocação à visão linear e diacrônica que aprendemos a reproduzir no tratamento das obras de arte. Além disso, a sugestiva aproximação entre a criação do trovador e a do compositor contemporâneo funde um gênero artístico hoje considerado erudito e um outro tradicionalmente relacionado à indústria cultural, e reputado menos nobre, talvez, por frequentar o terreno impuro dos

\footnotetext{
${ }^{3}$ As origens das citações foram buscadas nas referências expressas de fragmentos de canções e poemas, além da correspondência visual entre textos e autores na composição gráfica de "Coisa". Mais recentemente, num comentário acerca de sua relação crítico-criativa com a música popular, publicado no website Mappe Sonore, Augusto de Campos confirma os resultados de nossa pesquisa: "A esses meus exercícios-homenagens veio-se acrescer um poema ("coisa") diretamente inspirado por uma das composições de Cole — "What Is This Thing Called Love" e no qual reúno os "trovadores" Arnaut Daniel e Bernart de Ventadorn, Dante e Guido Cavalcanti, Cole Porter e Jimi Hendrix numa conversa imaginária e intemporal sobre a natureza dessa "coisa" ou "accidente (na expressão de Guido) chiamato amore". Em torno desse tema coincidente giram as referências a Bernart "lauzeta" (cotovia), da canção "Can vei la lauzeta mover" — e a Jimi — "little wing"; a Arnaut — "l'olors de noigandres" ou "d'enoi gandres" (o perfume que livra do tédio), "o sol chove" (lo soleils plovil), "l'aur'amara" (o ar amargo) —, a Dante - "l'amor che move il sole e l'altre stelle", "dove il sol tace" (onde o sol cala), "l'aer", (o ar) - e a Guido Cavalcanti — "Donna mi prega/ perch'io voglio dire/ d'un accidente/ che soventel è fero/ ed $\grave{e}$ sì altero/ ch'è chiamato amore". Cf. CAMPOS, Augusto de. Beba Cole. Disponível em: http://mappesonore.altervista.org/dettagli/view contributi.php?libro id=BK_CPORTER. Acesso em: 15 out. 2011.

${ }^{4}$ Não há dúvida de que, semioticamente, poema e canção são objetos distintos. Entendemos, contudo, que só por preconceito ou desconhecimento das origens do gênero lírico se pode rejeitar a hipótese de algumas canções abrigarem composições poéticas em seu componente textual.

${ }^{5}$ Referimo-nos, nessa passagem, à caracterização tradicional do gênero lírico, em que o termo se associa simultaneamente à musicalidade e à poesia de expressão subjetiva. Para uma conceituação mais ampla e cuidadosa, remetemos ao estudo de Francisco Achcar, Lírica e lugar-comum: alguns temas de Horácio e sua presença em Português (Edusp, 1994. Cf. referências bibliográficas no final deste artigo), especialmente em sua Parte I, intitulada "Gênero e Tópica".

${ }^{6}$ São de Augusto de Campos esta e todas as demais traduções de poemas reproduzidas neste artigo.
} 
meios de comunicação de massa. O que chama a atenção aqui é que, ao invés de se confrontarem num procedimento parodístico, como vemos acontecer nas várias manifestações das vanguardas da primeira metade do século $\mathrm{XX}$, os dois contextos estéticos se fundem de modo harmonioso, como a decretar, simplesmente, a inexistência de qualquer estratificação de gênero entre eles. A técnica de composição de "Coisa" remete assim, por analogia, a um texto bem anterior de Augusto de Campos, o poema "Soneterapia 2" (1993, p. 349):

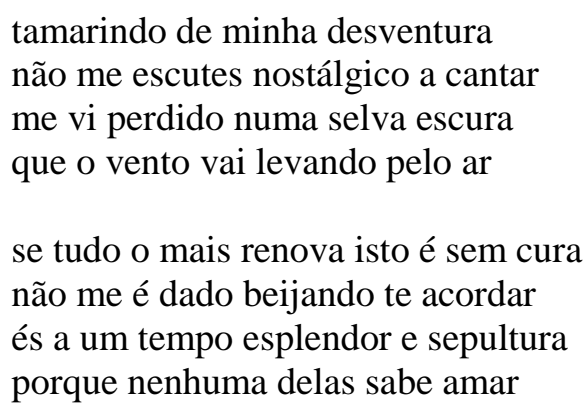

somente o amor e em sua ausência o amor guiado por um cego e uma criança deixa cantar de novo o trovador

pois bem chegou minha hora de vingança vem vem vem vem vem sentir o calor que a brisa do brasil beija e balança

Trata-se, como se vê, de um soneto em decassílabos, montado a partir da colagem de versos alheios, oswalduchampianamente. Ali se encontram, como explica o autor, poetas de épocas diversas, de Dante ("me vi perdido numa selva escura") a Décio Pignatari ("apenas o amor e em sua ausência o amor"), passando por Sá de Miranda ("se tudo o mais renova isto é sem cura"), Castro Alves ("que a brisa do Brasil beija e balança") e Augusto dos Anjos ("pois, bem, chegou minha hora de vingança") entre outros. Percebe-se a matriz de "Coisa", tanto no recurso à técnica de colagem, que atenta contra o conceito de autoria, como na seleção dos autores citados, que também equipara poetas clássicos e compositores populares nas referências a Orestes Barbosa e Sílvio Caldas ("Serenata"), Tom Jobim e Vinícius de Moraes ("A felicidade"), Ary Barroso ("Aquarela do Brasil"), João de Barros e Pixinguinha ("Carinhoso"), etc. Entretanto, se esse texto de 1973 é combativo, irônico, uma injeção de vida (ou de veneno) no gênero fóssil, preparada desde o trocadilho do título, a atmosfera de "Coisa" é intimista; se aquele poema se apresenta deliberadamente musical, este de que ora nos ocupamos investe numa relação diagramática entre som e visualidade, podendo ser comparado tecnicamente a algo entre sampling e mosaico. Assim, no plano sonoro, os fragmentos se atritam, harmonizando através do ritmo ("il sole / qual a chave / o que for / called love"), sobretudo das rimas (thing / $i$ ching / wing; move / chove / love / trove; Arnaut / about), estilhaços de línguas distintas, de épocas distintas, de estilos distintos; no plano visual, os tipos gráficos descrevem igualmente uma viagem no tempo, variando desde um aspecto arcaizante, que passa pela sofisticação e nobreza das serifas, até um certo efeito op art que marcou as artes gráficas dos anos 50-60. Da poesia secular (e atualíssima) de Provença ao psicodelismo da "era do Rock". Dessa forma, "Coisa" atualiza tema e

\footnotetext{
${ }^{7}$ Numa de suas edições, "Soneterapia 2" aparece acompanhado da rubrica "para ser parcialmente cantado" (Cf. CAMPOS, op. cit., 1993). No espetáculo multimídia "Poesia é Risco" (1994), o poeta realiza essa performance.
} 
procedimento de "Soneterapia 2", conferindo-lhes a dimensão que o próprio Augusto, definindo a natureza semiótica do poema concreto, chamou de verbivocovisual.

Por esse critério da sincronia, ${ }^{8}$ esclarece-se a lógica que harmoniza o painel aparentemente arbitrário de "Coisa": todos aqueles nomes citados, dos provençais a Dante, e deste aos músicos do século XX, são de representantes de formas artísticas em que se fundem palavra e ritmo, seja pela musicalidade do verso ou pelo canto, em sentido estrito. O poeta sublinha assim uma característica que, remontando às origens da Lírica, vem atualizar-se na poesia de nosso tempo. Ressalte-se, a propósito, que a palavra relativa ao fazer poético, no texto de Augusto de Campos, é significativamente o verbo "trovar", conjugado em primeira pessoa. É, portanto, na trilha dos trovadores, que se decifrarão mais algumas peças do mosaico: no terceiro verso, o fragmento l'olors (o olor), associado visualmente ao nome de Arnaut Daniel (sexta linha), remete à primeira estrofe do poema Er vei vermeills, vertz, blaus, blancs, gruocs ("Vermelho e verde e branco e blau", na transcriação de Augusto) (CAMPOS, A., 1987, p. 110-111).

\author{
Vermelho e verde e branco e blau, \\ Vergel, vau, monte e vale eu vejo, \\ A voz das aves voa e soa, \\ Em doce acordo, dia e tarde; \\ Então meu ser quer que eu colora o canto \\ De uma flor cujo fruto seja amor, \\ Grão, alegria e olor de noigandres... ${ }^{9}$
}

Do mesmo Arnaut Daniel, temos ainda a célebre Aura amara tangenciada num pequeno fragmento na sétima linha (aur'), seguido de variações linguísticas do conceito "ar", em que sopra a brisa (l'aura) que o poeta medieval desentranhara do nome da musa (Laura), como anotou Augusto de Campos (1988, p. 44). E também a frase "o sol chove" (quinta linha), em relação complementar, ou de contraste, com "o sol cala", de Dante. O próprio Augusto refere, em mais de um texto crítico, a expressão, já sublinhada por Pound, "Il miglior fabbro del parlar materno" (o melhor artífice da língua materna), com que Dante saúda Arnaut no Canto XXVI do Purgatório (POUND, 1995, p. 53). A admiração que o poeta da

\footnotetext{
${ }^{8}$ Servimo-nos aqui do conceito de poética sincrônica, conforme concebido por Haroldo de Campos, apoiando-se numa proposição de Jakobson, que escrevera: "A descrição sincrônica considera não apenas a produção literária de um período dado, mas também aquela parte da tradição literária que, para o período em questão, permaneceu viva ou foi revivida" (apud CAMPOS, Haroldo de. 1977 p. 207). Adiante, o crítico brasileiro reelabora e exemplifica o conceito: "A poética sincrônica (estético-criativa), no sentido em que a conceituo para propósitos bem definidos, está impreterivelmente vinculada às necessidades criativas do presente: ela não se guia por uma descrição sincrônica estabelecida no passado, mas quer substituí-la — para efeitos inclusive de revisão do panorama diacrônico rotineiro - por uma nova tábua sincrônica que retira sua função da literatura viva do presente. Poética sincrônica faz um Eliot quando reabilita os 'poetas metafísicos', um Garcia Lorca quando revê Gôngora, um Pound quando reedita Cavalcanti, a poesia concreta quando reclama a reavaliação de Sousândrade ou de Kilkerry." (Op. cit., p. 222-223).

${ }^{9}$ A expressão grifada tornou-se conhecida entre nós através dos poetas concretos que, ao que assinalam, colheram-na do poema XX d'Os Cantares, de Ezra Pound. O texto de Pound comenta, em estilo anedótico, a dificuldade de tradução da forma provençal enoi gandres pelo romanista alemão Emil Levy (POUND, 1985). Atraídos pelo mistério dessa palavra-enigma, Augusto de Campos, Haroldo de Campos e Décio Pignatari tomaram-na como símbolo de experimentalismo (vale dizer, da busca de uma beleza difícil) e a adotaram como nome do grupo e da revista de vanguarda que, nos anos 50, divulgaria os primeiros textos do movimento da Poesia Concreta.
} 
Comédia nutria pelo trovador provençal autoriza a aproximação dos fragmentos, como se vê nas passagens seguintes, do Canto I do Inferno, na Divina Comédia, e da canção Lancan son passat li giure ("Quando já se vai a neve").

Tal como a gente rica perde a cor quando sente a fortuna abandoná-la que só sabe chorar a sua dor, assim a fera me deixou sem fala, e, vindo ao meu encalço, a Loba atroz me encurralava lá, onde o Sol cala. (Dante).

Bertran, ninguém já conheceu uma alegria tamanha, do Nilo, onde o sol se banha, até lá, onde o sol choveu. (Arnaut Daniel).

As demais referências a Dante se aproximam - a ponto de quase se confundirem visual e conceitualmente - de alusões a outro trovador, Guido Cavalcanti, em fragmentos que remontam ao célebre "o amor que move o sol e as outras estrelas", do primeiro, e ao "acidente geralmente forte / e de tal porte / que é chamado amor", deste último. Por fim, o tipo espiralado e sinuoso das expressões "coisa, acaso, i ching", "qual a chave", "o que for" e "dói para que eu trove" contrasta com os demais fragmentos, já que não se identifica visualmente com nenhum dos nomes expressos no texto. Esse eixo discursivo do poema - o componente que visualmente se distingue das apropriações deliberadas e que representaria, formalmente, o contraponto musical do eu lírico - esconde, entretanto, um novo link hipertextual que, justamente por estar elíptico, se torna ainda mais instigante: a segunda linha do poema ("Coisa acaso i ching") configura uma semântica da indeterminação, da aleatoriedade e do orientalismo - conceitos que, ao que indicam vários textos críticos de Augusto de Campos, aportaram em sua obra a partir do contato com a postura estéticofilosófica do músico e poeta norte-americano John Cage. Em seu ensaio de "anticrítica" Cage: chance: change, (1986, p. 211-227), Augusto escreveu:

\author{
reagindo contra o conceito de música \\ totalmente predeterminada, \\ levado às últimas consequências pelos jovens serialistas \\ pós-weberianos (boulez, stockhausen) \\ cage cria a "música indeterminada". \\ desde 1950 começara a desenvolver \\ a sua teoria da indeterminação em música \\ derivou-a do i ching \\ o clássico livro-de-oráculos chinês \\ mediante operações de acaso \\ a partir do $\boldsymbol{i}$ ching (livro das mutações) \\ compôs, em 1952, music of changes (música das mutações) \\ com sons e silêncios distribuídos casualmente.
}

A influência exercida por "Cage" sobre a poesia de Augusto de Campos tem ensejado tanto citações expressas, caso dos poemas "Hom'Cage to Webern" (1972), "Pentahexagrama para John Cage" (1977) e "Todos os sons" (1979), quanto alusões implícitas, sob a forma de estilização de procedimentos, como em "Acaso" (1963) e "Cidade" 
(1963). Diante disso, justifica-se considerarmos, também aqui, a presença dialógica de Cage, na forma de uma interpretação livre de suas lições pelo poeta paulista. Assim é que os fragmentos em tipos variados de "Coisa" simulam uma colagem aleatória de recortes (samples) gráficos (musicais); as rimas translinguísticas carregam uma reflexão, muito cara também ao músico norte-americano, sobre o papel do artista como manipulador do acaso, aqui materializado no confronto entre a arbitrariedade dos códigos e as coincidências semântico-sonoras desveladas pelo poeta.

\section{2. "Qual a chave?"}

Percorridas as trilhas do intertexto, retornemos ao primeiro e mais inquietante dos enigmas do poema: o da indeterminação de sua chave temática. Contrariando a função que tradicionalmente se atribui ao título num texto literário, o poeta recorre, neste caso, a uma hiperonímia que mais intriga do que orienta o leitor: afinal, que "coisa" é essa de que fala o poeta? Seguindo o percurso que até aqui fizemos, ao menos três eixos semânticos se ramificam desde essa palavra, numa configuração em que o tema do enigma envolve os outros dois, quais sejam o do amor e o do trovar (canção/ poesia). O que ocorre é que, transposta para a forma de expressão, a imprecisão do objeto gera uma forma de composição que é ela mesma indefinível, procedimento pelo qual o poeta compartilha com o leitor a experiência do estranhamento de que figuradamente se encontra tomado, lançando-nos também diante de um enigma, que é o próprio ícone do enigma tematizado.

Já a isotopia do amor remete a um tópos lírico, o da intraduzibilidade desse sentimento. Acolhendo-a, o poema de Augusto de Campos se conecta a uma tradição de textos que, ao descrever esse estado subjetivo, fingem negar-se a revelar os contornos do próprio objeto: poemas da imprecisão, do não-sei-quê. ${ }^{10}$ Assim, todas as citações de nomes e fragmentos de versos dispersos em "Coisa" podem ser lidas como uma enumeração de sujeitos antepostos a um só predicado: “... dói para que eu trove”. A existência dessa tópica implicando muitas vezes apropriação, tanto do assunto como de expressões, e até de versos inteiros dos poemas imitados — pode nos levar a uma curiosa cadeia em que cada poeta recorre à palavra de seu precursor justamente para definir o que afirma ser indefinível. Neste exemplo específico, Augusto de Campos radicaliza o procedimento, citando não apenas um autor, mas toda uma linhagem de autores que se lançaram à difícil tarefa. Não se espere, contudo, que o poeta contemporâneo se contente com a estilização passiva do discurso da tradição: avesso à discursividade, ele se desincumbe de glosar o tema em torneios retóricos, optando pelo gesto crítico de desfilar aos nossos olhos (e ouvidos) séculos de poesia sobre essa suposta intraduzibilidade - ao mesmo tempo em que constrói, na entropia do aparente caos linguístico, um ícone do seu objeto. Lido nesta chave, "Coisa" configura-se como um exercício de poética sincrônica - uma espécie de antologia afetiva (mas essencialmente crítica) regida pelos critérios da musicalidade e do lirismo amoroso - um cantar de amor sobre os cantares de amor: vale dizer, um trovar (certamente do gênero chamado "fechado" ou difícil) cujo objeto é a pura sensação do intraduzível que, no entanto, ele nos comunica: seja na chave da poesia dos músicos ou na da música dos poetas.

\footnotetext{
${ }^{10}$ Para fim de comparação, considerem-se outros exemplos de temática semelhante, como os sonetos de Luís de Camões "Tanto de meu estado me acho incerto" (este já uma paráfrase de Petrarca), e "Busque Amor novas artes, novo engenho", com sua emblemática chave de ouro: "um não sei quê que nasce não sei onde, / vem não sei como e dói não sei por quê".
} 
CASA, Vol.9 n.2, dezembro de 2011

\section{REFERÊNCIAS}

ACHCAR, Francisco. Lírica e lugar-comum: alguns temas de Horácio e sua presença em português. São Paulo: Edusp, 1994.

CAGE, John. De segunda a um ano; novas conferências e escritos de John Cage. Trad. de Rogério Duprat. São Paulo: Hucitec, 1985.

CAMPOS, Augusto de. Balanço da bossa e outras bossas. 5 ed. São Paulo: Perspectiva, 1993.

. O anticrítico. São Paulo: Companhia das Letras, 1986.

. Despoesia. São Paulo: Perspectiva, 1994.

. Mais provençais. São Paulo: Companhia das Letras, 1987.

. Verso reverso controverso. 2 ed. São Paulo: Perspectiva, 1988.

CAMPOS, Augusto de \& CAMPOS, Haroldo de. Traduzir e trovar (poetas do século XII a XVII). São Paulo: Papyrus, 1968.

CAMPOS, Haroldo de. A arte no horizonte do provável. 4 ed. São Paulo: Perspectiva, 1977. POUND, Ezra. ABC da literatura. 7 ed. São Paulo: Cultrix, 1995.

Poesia. Trad. de Augusto e Haroldo de Campos, Décio Pignatari, J. L. Grünewald e Mário Faustino. 2 ed. São Paulo: Hucitec, 1985. 